\title{
Vibroacoustics and psychoacoustics investigation of biodegradable composites for musical instruments
}

\author{
Jorge Segura Alcaraz ${ }^{1}$, José María Gadea Borrell ${ }^{1}$, Ernesto Juliá Sanchis ${ }^{1 *}$, José Enrique Crespo Amorós1 ${ }^{1}$, Isaac \\ Montava Belda ${ }^{1}$, Sofía Rebagliato Torregrosa ${ }^{1}$
}

${ }^{1}$ Universitat Politècnica de València, Campus d'Alcoi, Spain

\begin{abstract}
Due to the extinction of some wood species used to manufacture guitars, there is a trend to search new alternative materials with the same acoustic performance. There is a wide range of tonewoods: ebony, rosewood, yellow and red cedar, mongoy and sapelli, among others. These woods have high resonance qualities and the requirements are both acoustical and mechanical. In this work, alternative composite materials have been manufactured to compare dynamic and psychoacoustic parameters with the commonly used woods. This comparison will allow to conclude the possibility of using these materials as substitutive of tonewoods.
\end{abstract}

\section{Introduction}

Deforestation in some parts of the planet is becoming a threat for the use of some woods in musical instruments, specially the tropical species. The current situation makes a need of substituting these materials for these applications. Some researchers focus their works on other types of wood [1] [2].

In this work, the vibroacoustic parameters of biodegradable materials, as substitutive of woods, are studied. Table 1 shows some common woods used for guitars:

Table 1. Commonly used woods.

\begin{tabular}{|c|c|}
\hline Material & Density $\left(\mathbf{g} / \mathbf{c m}^{\mathbf{3}}\right)$ \\
\hline German Fir & 0,325 \\
\hline Sitka Fir & 0,274 \\
\hline Engelmann Fir & 0,296 \\
\hline Red Cedar & 0,283 \\
\hline Yellow Cedar & 0,299 \\
\hline Mongoy & 0,807 \\
\hline Sapelli & 0,624 \\
\hline
\end{tabular}

Other authors focus their investigation on alternative materials to wood ([3][4]).

Table 2 shows the characteristics of the three materials manufactured as alternative to woods.

Table 2. Alternative materials.

\begin{tabular}{|c|c|}
\hline Material & Density $\left(\mathbf{g} / \mathbf{c m}^{\mathbf{3}}\right)$ \\
\hline Thick wool & 1,1 \\
\hline Hemp & 1,07 \\
\hline Jute & 1,42 \\
\hline
\end{tabular}

With these materials, the goals of the investigation are:

- $\quad$ To compare the results of the FFT.

- $\quad$ To compare the psychoacoustic parameters.

The results will allow to evaluate the possibilities of using these alternative materials.

\subsection{Psychoacoustics parameters}

Noise is defined as an audible sound which disturbs the silence or leads to annoyance. The evaluation of noise depends on the physical characteristics of the sound, on the psychoacoustical features of the human ear and on the psychological aspects of people [5]. The main psychoacoustic parameters are the following:

\subsubsection{Loudness}

The loudness is a subjective measurement of the content of energy of a perceived sound. It is related to the decibel as it ranges from strong to weak sounds.

\subsubsection{Sharpness}

Sharpness is the frequency content of a sound. A sound with higher frequencies is sharper.

\subsubsection{Tonality}

Tonality is a quality that allows to classify a sound from low to high frequencies.

\footnotetext{
* Corresponding author: erjusan@mes.upv.es
} 


\subsubsection{Roughness}

Roughness is the subjective perception of the amplitude changes. It depends on the modulation of the frequency and on the sound level pressure.

\section{Materials and Methods}

\subsection{Manufacturing}

To manufacture the samples, the Vacuum Infusion Process (VIP) technique has been used. It is a method to manufacture composite materials reinforced with fibers. This process utilizes the atmospheric pressure to push the resin into the mold cavity. A polystyrene resin is used as cohesive material.

The process consists of impregnating a dry preformed fiber with a thermosetting resin of low viscosity, by a pressure difference between the cavity of the preform and the deposit of the resin, sealed with a vacuum bag. The pressure difference is made by means of a vacuum pump, which forces the resin to move gradually inside the cavity.

This process requires a control over the time of impregnation of the fibers, not being too fast (which would cause porosity) or too slow (causing a cure that prevents the advance of the resin in the preform). Figure 1 shows the manufacturing process of one of the samples.

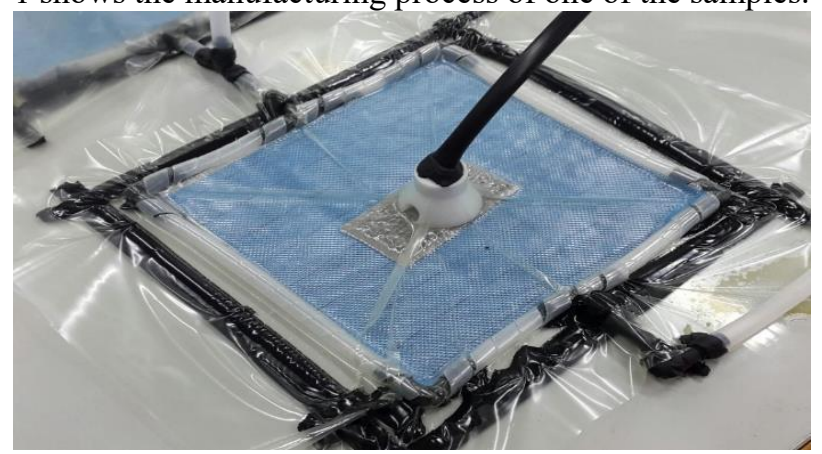

Fig. 1. Vacuum Infusion Process (VIP).

Figure 2 shows the three test samples manufactured.

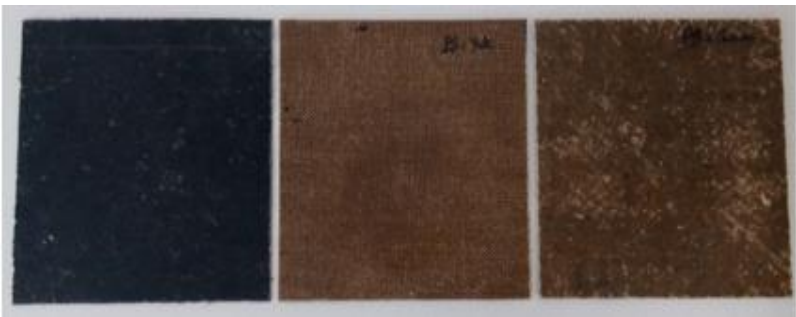

Fig. 2. The three test samples: thick wool, hemp and jute (left to right).

\subsection{Experimental Tests}

Two different tests have been carried out to determine the acoustic parameters required to compare the materials:

\subsubsection{First experimental set-up.}

Figure 3 shows the first experimental set-up for a dynamic test. The FFT is obtained by means of this test.

The working conditions of the shaker are: $5 \mathrm{~Hz}, 4 \mathrm{~V}$ and $0,33 \mathrm{~A}$.

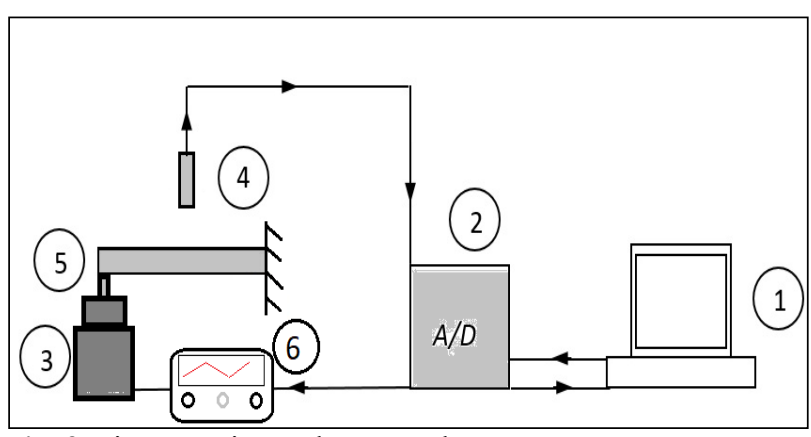

Fig. 3. First experimental set-up scheme.

The equipment consists in:

1) Computer,

2) Data acquisition card,

3) Shaker,

4) Microphone,

5) Test sample and

6) Function generator.

\subsubsection{Second experimental set-up}

Figure 4 shows the scheme of the experimental set-up to determine the psychoacoustic parameters.

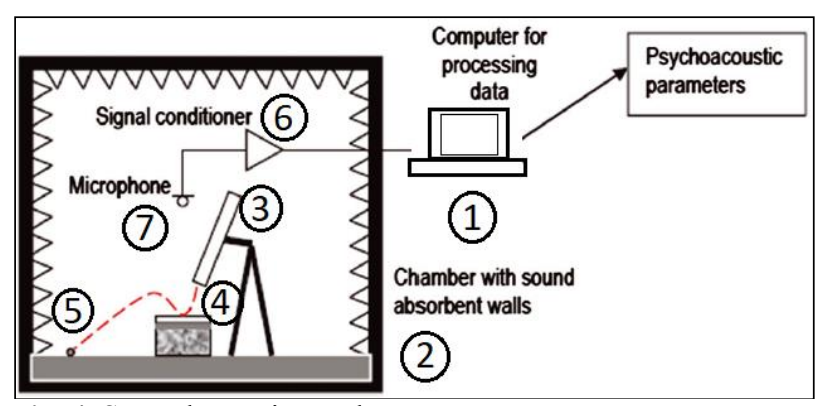

Fig. 4. Second experimental set-up.

Where:

1) Computer,

2) Anechoic chamber,

3) Tube to throw the impact steel ball,

4) Test sample,

5) Impact steel ball,

6) Signal conditioner and

7) Microphone. 


\section{Results}

\subsection{Dynamic results}

To compare the behaviour of the materials, the FFT are represented in Figures 5 to 11 . The frequency range is from $20 \mathrm{~Hz}$ to $4200 \mathrm{~Hz}$, which is inside the human hearing field. The reference is a piano which is from $27,5 \mathrm{~Hz}$ to $4186 \mathrm{~Hz}$.

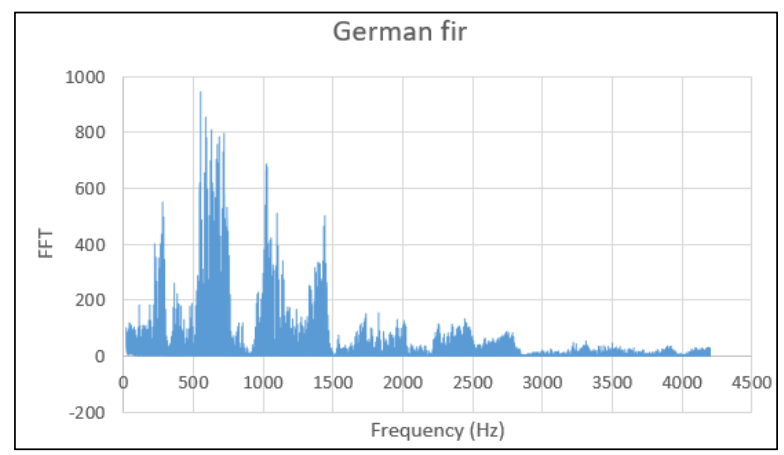

Fig. 5. FFT graph of german fir wood.

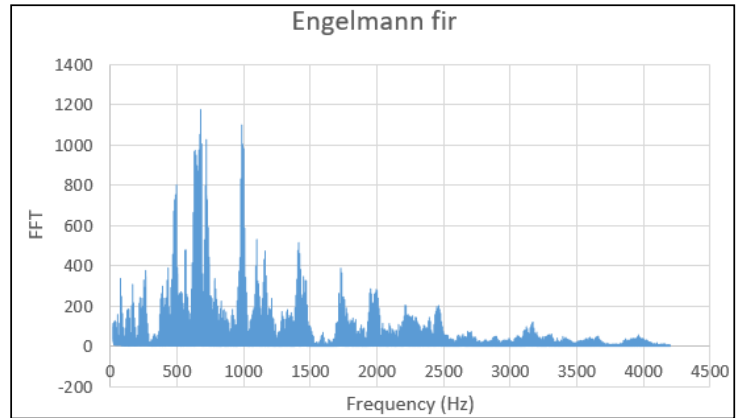

Fig. 6. FFT graph of Engelmann fir wood.

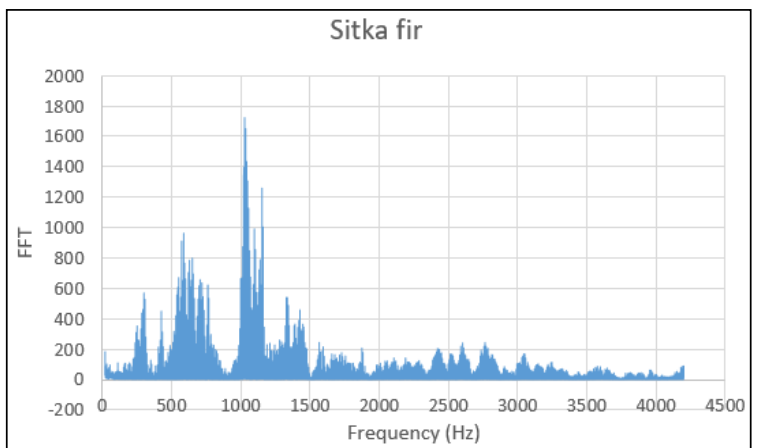

Fig. 7. FFT graph of Sitka fir wood.

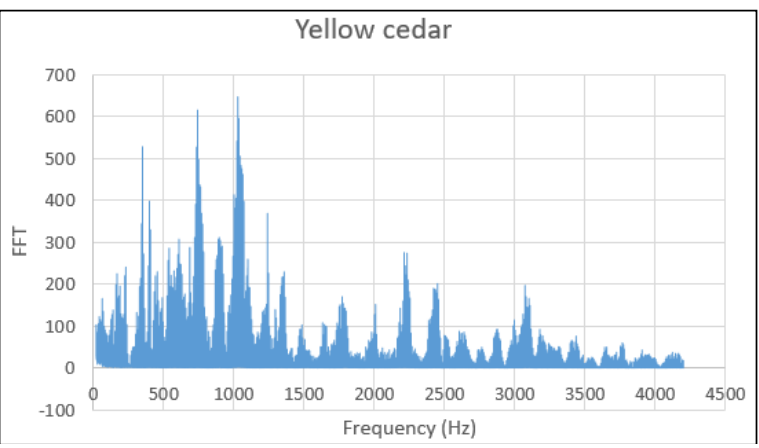

Fig. 8. FFT graph of yellow cedar wood.

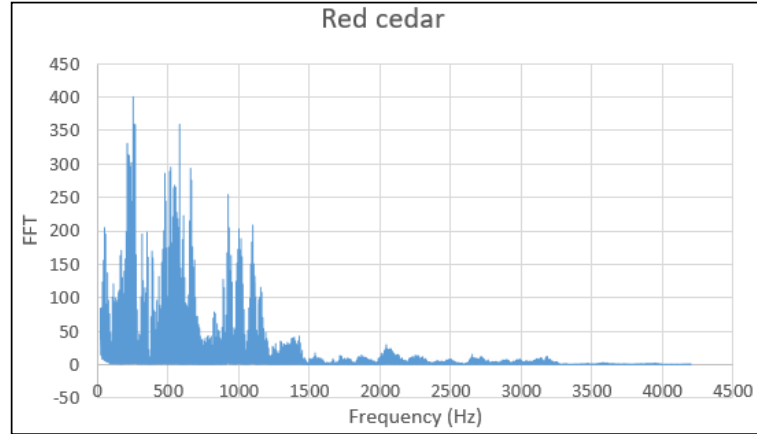

Fig. 9. FFT graph of red cedar wood.

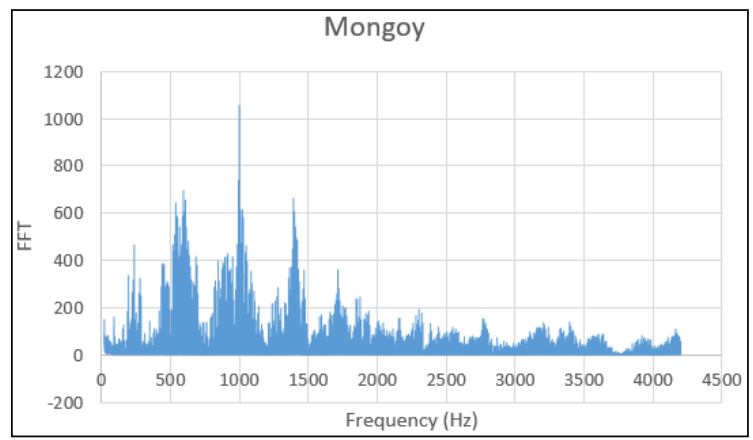

Fig. 10. FFT graph of Mongoy wood.

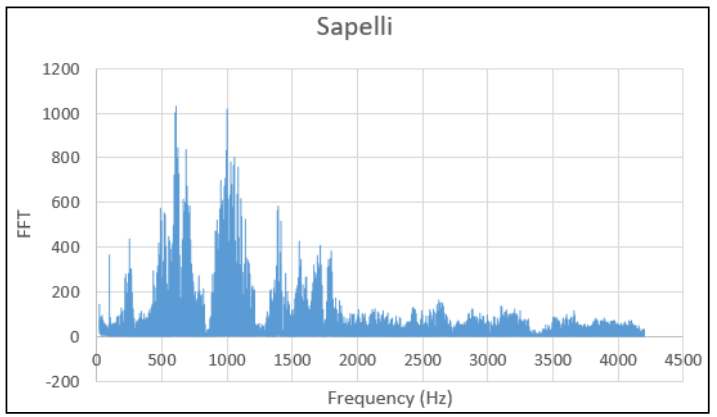

Fig. 11. FFT graphs of the Sapelli wood

The same analysis is carried out for the alternative materials: thick wood, hemp and jute (Figures 12 to 14), so that the FFT graphs are compared to the new materials.

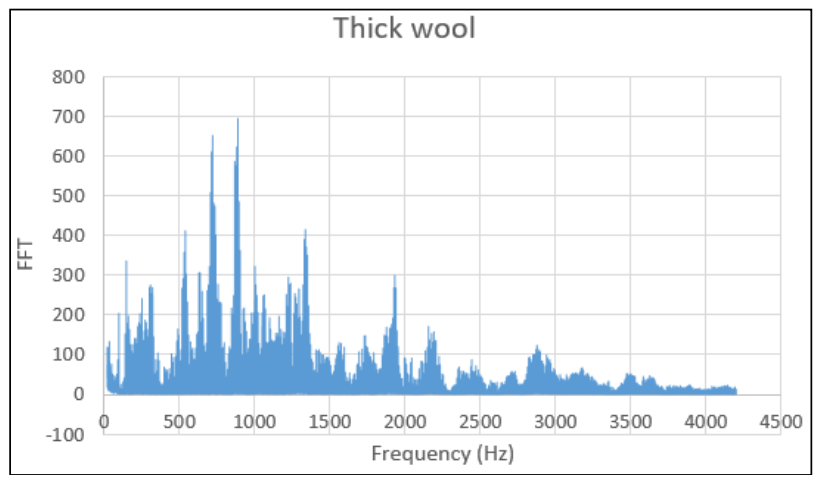

Fig. 12. FFT graph of thick wool. 


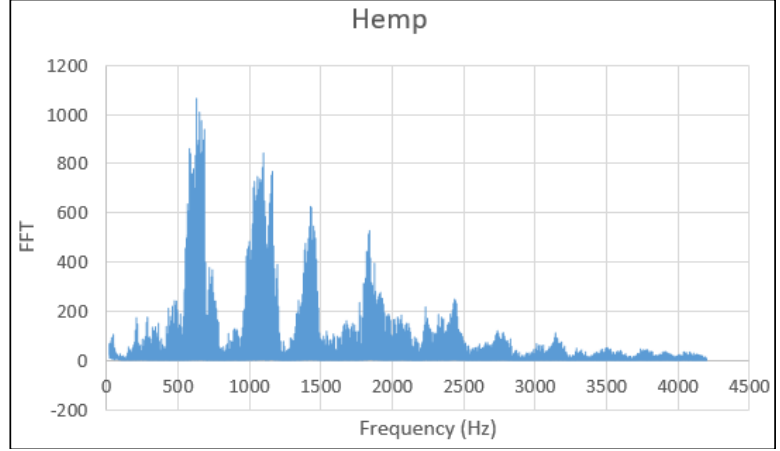

Fig. 13. FFT graph of Hemp.

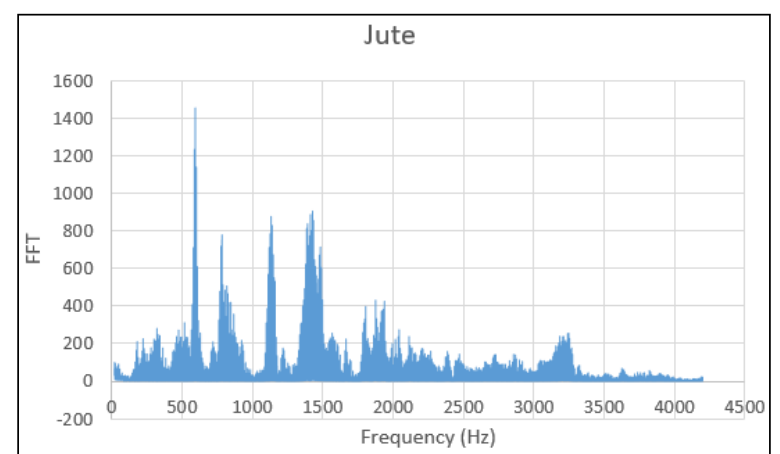

Fig. 14. FFT graphs of jute.

\subsection{Psychoacoustic results}

For the psychoacoustic parameters there are results from a survey in which people compare the subjective sensation. Other parameters are obtained with software dBFA.

Tables 3 and 4 show the psychoacoustic results for the common woods and for the new materials, respectively.

Table 3. Psychoacoustics results of common woods.

\begin{tabular}{|c|c|c|c|c|c|c|c|}
\hline $\begin{array}{c}\text { Psychoacoustics } \\
\text { Criteria }\end{array}$ & $\begin{array}{c}\text { German } \\
\text { fir }\end{array}$ & $\begin{array}{c}\text { Engelmann } \\
\text { fir }\end{array}$ & $\begin{array}{c}\text { Sitka } \\
\text { fir }\end{array}$ & $\begin{array}{c}\text { Yellow } \\
\text { cedar }\end{array}$ & $\begin{array}{c}\text { Red } \\
\text { cedar }\end{array}$ & Mongoy & Sapelli \\
\hline Loudness & 36,6225 & 37,2675 & 33,665 & 33,5125 & 33,57 & 38,2 & 37,09 \\
\hline Sharpness & 1,365 & 1,2875 & 1,2775 & 1,3175 & 1,2625 & 1,4025 & 1,415 \\
\hline Tonality & 0,5925 & 0,685 & 0,6675 & 0,775 & 0,6475 & 0,3875 & 0,755 \\
\hline Roughness & 1,115 & 1,12 & 1,01 & 1,1825 & 1,1925 & 1,14 & 1,21 \\
\hline Subjective sensation & 0,19 & 0,215 & 0,2725 & 0,2425 & 0,2425 & 0,1475 & 0,185 \\
\hline
\end{tabular}

Table 4. Psychoacoustics results of the new materials.

\begin{tabular}{|c|c|c|c|}
\hline $\begin{array}{c}\text { Psychoacoustics } \\
\text { Criteria }\end{array}$ & Hemp & Wool & Jute \\
\hline Loudness & 34,765 & 29,515 & 35,49 \\
\hline Sharpness & 1,72 & 1,41 & 1,59 \\
\hline Tonality & 0,25 & 0,615 & 0,505 \\
\hline Roughness & 1,525 & 1,45 & 1,115 \\
\hline Subjective sensation & 0,075 & 0,19 & 0,155 \\
\hline
\end{tabular}

\section{Conclusions}

It can be concluded that the thick wool material has a similar behaviour to Engelmann fir and yellow cedar woods. The most representative peaks are at $500 \mathrm{~Hz}$, $700 \mathrm{~Hz}, 900 \mathrm{~Hz}, 1300 \mathrm{~Hz}, 1900 \mathrm{~Hz}$ y $2900 \mathrm{~Hz}$.

For this reason, these materials present more representative peaks in the audible range and have harmonics wider and balanced.

After the study, the thick wool composite material would be applicable as an alternative to the commonly used woods in musical instruments.

\section{References}

[1] B. C. Bennett, "The Sound of Trees: Wood Selection in Guitars and Other Chordophones," Econ. Bot., vol. 70, no. 1, pp. 49-63, 2016.

[2] U. G. K. Wegst, "Wood for sound," Am. J. Bot., vol. 93, no. 10, pp. 1439-1448, 2006.

[3] J. A. Decker, "Production technology: Commercial composite-materials acoustic guitars," Evol. Technol. Compet. Edge, Books 1 2, vol. 42, p. 582-592\r1572, 1997.

[4] J. A. Torres and R. Torres-Martínez, "Evaluation of Guitars and Violins Made using Alternative Woods through Mobility Measurements," Arch. Acoust., vol. 40, no. 3, pp. 351-358, 2015.

[5] K. Genuit and A. Fiebig, "Prediction of psychoacoustic parameters," J. Acoust. Soc. Am., vol. 118, no. 3, pp. 1874-1874, 2005. 